Original Research Article

\title{
Accidental tramadol ingestion in children admitted in tertiary care centre
}

\author{
Vadlakonda Sruthi ${ }^{1}$, Annaladasu Narendra ${ }^{2} *$
}

${ }^{1}$ Department of Pharmacology,

${ }^{2}$ Department of Paediatrics, Osmania Medical College, Hyderabad, Telangana, India

Received: 25 October 2019

Revised: 08 November 2019

Accepted: 11 November 2019

*Correspondence to:

Dr. Annaladasu Narendra, Email: dr.narendrambbs @gmail.com

Copyright: (C) the author(s), publisher and licensee Medip Academy. This is an openaccess article distributed under the terms of the Creative Commons Attribution NonCommercial License, which permits unrestricted noncommercial use, distribution, and reproduction in any medium, provided the original work is properly cited.

\begin{abstract}
Background: Tramadol use has been increasing in the adult and pediatric population. Practitioners must be alert because Tramadol misuse can lead to severe intoxication in which respiratory failure and seizures are frequent. Overdoses can lead to death. We report 47 pediatric cases with history of accidental tramadol exposure in children.

Methods: An observational, retrospective, single center case -series of children with a history of accidental tramadol exposure in children admitted in pediatric intensive care unit of tertiary care center, Niloufer Hospital (Osmania Medical College) Hyderabad, Telangana India.

Results: Of 47 children, $22(47 \%)$ are male and $25(53 \%)$ were female. At presentation $11(23 \%)$ had loss of consciousness, 14 (29\%) seizures, 17 (36\%) hypotonia was noted. Pupils were miotic in 22 (47\%) mydriatic in $2(4.2 \%)$ normal in rest of children. Hemodynamic instability noted in 13 (27.6\%). Serotonin syndrome (tachycardia, hyperthermia, hypertension, hyper reflex, clonus) was noted on $5(10.6 \%)$ children. Respiratory depression was seen in 4 $(8 \%)$ children who needed ventilatory support. Antidote Naloxone was given in 7 children. No adverse reaction was noted with Naloxone. All 47 children were successfully discharged.

Conclusions: Overdoses can lead to death and practitioners must be alert because of the increasing use of tramadol in the adult and pediatric population. The handling of the tramadol should be explained to parents and general population and naloxone could be efficient when opioid toxicity signs are present.
\end{abstract}

Keywords: Tramadol, Naloxone, Intoxication, Overdose, Intensive care units, Paediatric, Apnea

\section{INTRODUCTION}

Tramadol is a codeine analogue, common analgesic used for the management of mild to moderately severe acute pain. It is a central analgesic, works through two mechanisms according to its two enantiomers, $\mu$-opiate receptors agonists and serotonin and norepinephrine reuptake inhibition. ${ }^{1,2}$

It is metabolized in the liver through the cytochrome P450 CYP2D6 being the main metabolizer conducting the O-demethylation. The pharmacodynamically active metabolite seems to have a 200-300 higher affinity for $\mu$-opioid receptors than tramadol with elimination $\mathrm{t}_{1 / 2} 6 \mathrm{hr}$ for tramadol, $7.5 \mathrm{hr}$ for its active metabolite. ${ }^{3}$ The genetic polymorphism of those cytochromes explains the interindividual variability of tramadol pharmacokinetics. The usual dose is 1 to $2 \mathrm{mg} / \mathrm{kg}$ every 6 hours, not to exceed $8 \mathrm{mg} / \mathrm{kg} / 24$ hours, maximum adult dose is $400 \mathrm{mg}$.

Due to O-desmethyltramadol's affinity for the $\mu$-opiate receptors, an overdose can cause systemic symptoms such as nausea, vomiting, and respiratory or neurologic depression. ${ }^{4}$ Other clinical presentations include serotoninergic syndromes or tonic-clonic seizures. ${ }^{4-6}$ Tramadol use is increasing and case reports of misuse, overdoses, dependence are reported in adults in India. ${ }^{7}$ 
Intoxication is rare in the pediatric population and very few cases are reported. . $^{3-8-10}$ The objective of study was to determine the clinical manifestations of accidental tramadol exposure in children and adverse reactions with naloxone antidote.

\section{METHODS}

This was an observational, retrospective, single-center case-series of children with a history of accidental tramadol exposure in children admitted in pediatric intensive care unit (PICU) of Niloufer Hospital (Osmania Medical College) tertiary care Centre in March 2019, in Hyderabad, Telangana India. Cases were identified and reviewed from among all the hospitalized children who had ingested immediate-release tramadol tablet $(300 \mathrm{mg}$ ) at home provided by their parents unintentionally as antipyretic after child had fever following immunisation given by local paramedical staff at a health centre on 7 th March 2019. Unintentionally paramedical staff issued tramadol tablet instead of paracetamol because of similar appearance of strips which were broken into smaller strips. Parents were instructed to give $1 / 4^{\text {th }}$ tablet (300 $\mathrm{mg}$ ) in case if child develops fever.

All children who were admitted with history of accidental tramadol tablet ingestion following fever after immunization session at a Health Centre on 7th March 2019 were included in the study. Children who were immunized but no history of tablet ingestion but admitted for other reasons were excluded. We defined overdose as an excessive dose taken by the child. The usual dose is 1 to $2 \mathrm{mg} / \mathrm{kg}$ every 6 hours, not to exceed $8 \mathrm{mg} / \mathrm{kg} / 24$ hours. Intoxication was confirmed by quantitative blood sample and questioning the parents.

Descriptive version of SPSS 10.0 software used to analyze the data.

\section{RESULTS}

Of total 92 infants immunized at urban health centre, 47 cases of accidental tramadol ingestion were admitted in PICU of tertiary care centre in Hyderabad, Telangana, India.

Of 47 infants, $22(47 \%)$ are male and $25(53 \%)$ were female (Figure 1).

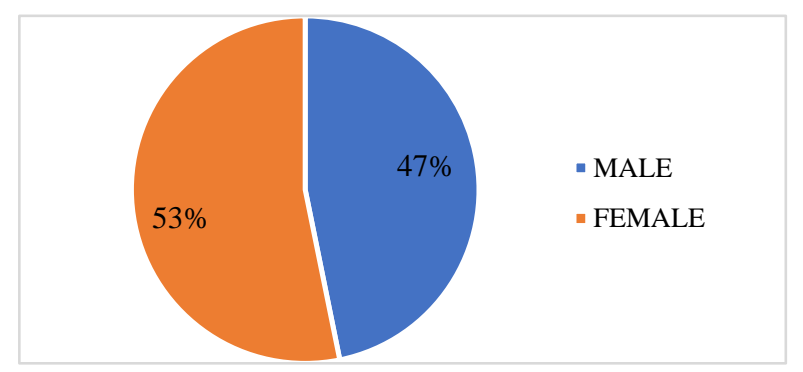

Figure 1: Gender distribution of cases.
Mean age of the patients was 10 weeks (range; 6 weeks to 16 months). $32(67 \%)$ cases were less than 3 months of age, 8 cases were 3 to 4 months age ,7 cases were $>4$ months age (Figure 2).

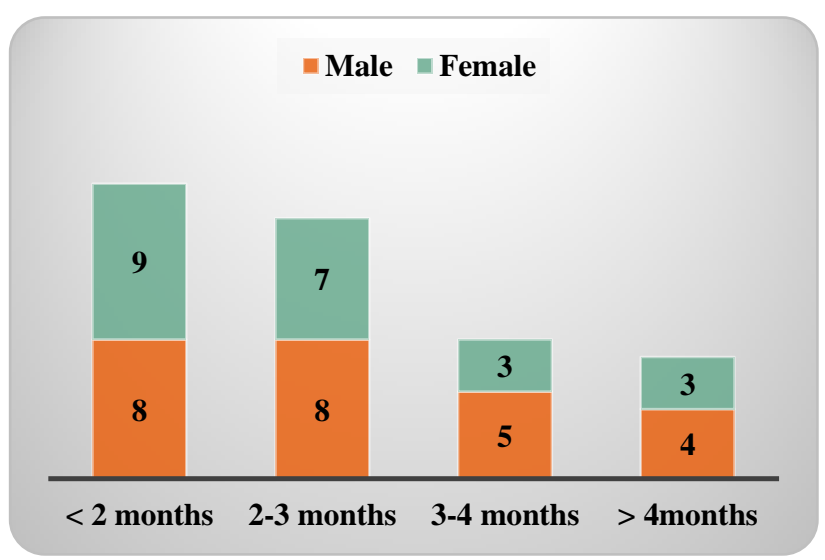

Figure 2: Age wise distribution of cases.

Mean time of exposure to onset of symptoms 10.5 hours (range $6.5 \mathrm{hrs} 14 \mathrm{hrs}$ ). Mean dose of tramadol received by infants is range $10.4 \mathrm{mg}(15.7-7.5 \mathrm{mg})$.

At presentation $11(23 \%)$ had loss of consciousness, seizures in 14 (29\%) hypotonia in 17 (36\%), hemodynamic instability was noted in 13 (27.6\%) children (Figure 3).

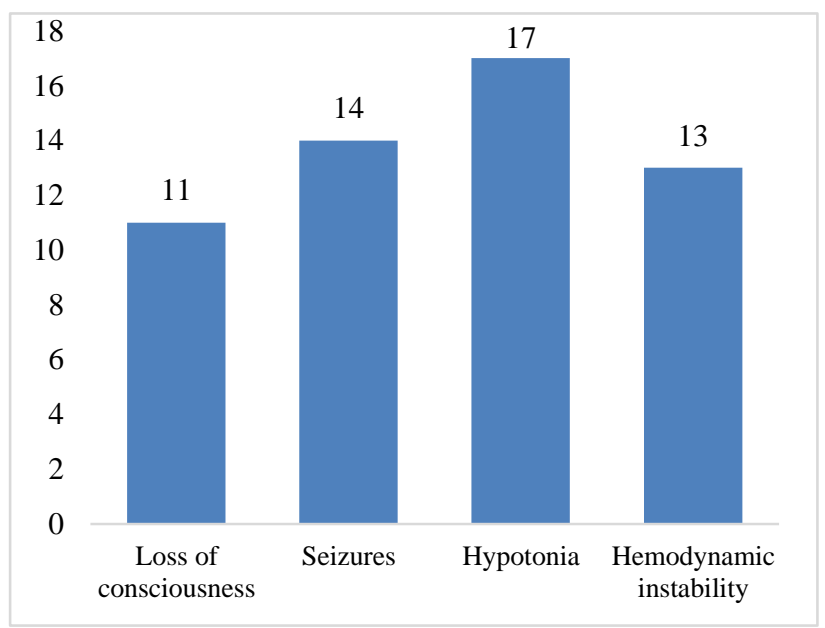

Figure 3: Clinical presentation at admission.

Pupils were miotic in $22(47 \%)$, mydriatic in $2(4.2 \%)$ normal in rest of infants (Figure 4).

Serotonin syndrome (tachycardia, hyperthermia, hypertension, hyper reflex, clonus) was noted on 5 $(10.6 \%)$ infants. Respiratory depression was seen in 4 $(8 \%)$ infants who needed ventilatory support. $6(12 \%)$ infants had drug induced hepatitis.

All children received treatment as per standard protocols. Antidote naloxone was given in 7 infants. 
Outcome of the study; No adverse reaction was noted with naloxone. All 47 infants were successfully discharged. 2 cases died before they reached the hospital.

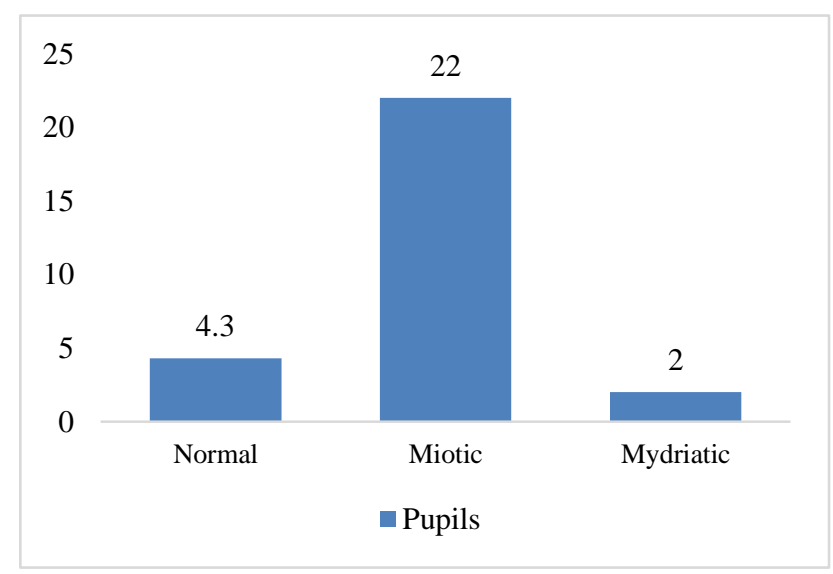

Figure 4: Condition of pupils at admission.

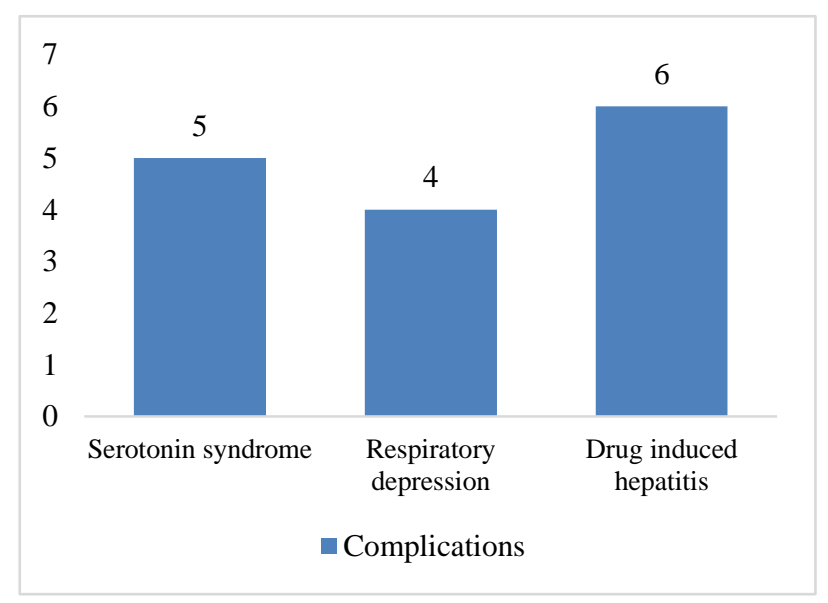

Figure 5: Complications during hospital stay.

\section{DISCUSSION}

Tramadol is a centrally acting, synthetic analgesic agent, although its metabolite has some affinities for $\mu$-opiate receptors, it exerts its analgesic effect by inhibiting the reuptake of norepinephrine and serotonin and by increasing their respective release or secretion. The recommended therapeutic dose in children is of $1-2 \mathrm{mg} / \mathrm{kg}$ every 6 hours. The peak serum level is attained in 30 minutes and it is subsequently eliminated by the renal route with an excretion half-life of 6 hours in children. The serum therapeutic levels are of 0.2 to $0.8 \mathrm{mg} / \mathrm{l}$, and toxicity is considered when above $1 \mathrm{mg} / \mathrm{l}^{2,12}$

In children only very few cases of acute tramadol poisoning have been reported. ${ }^{11}$ Tramadol poisoning can be daily treatment overdoses, accidental, or parenteral poisoning/ Munchausen syndrome by proxy. ${ }^{5,6,8-10} \mathrm{We}$ report 47 pediatric cases with history of accidental tramadol exposure in children admitted in PICU of tertiary care centre, India in March 2019.
In our case series respiratory depression was seen in 4 $(8 \%)$ children who needed ventilatory support. Seizures, was reported in 17 children $(36 \%)$. Srinivas et al confirmed respiratory depression and seizures as an effect of tramadol central action. ${ }^{13}$

Serotonin syndrome (tachycardia, hyperthermia, hypertension, hyper reflex, clonus) was noted on 5 $(10.6 \%)$ children in our study. Truncal rigidity can be seen in severe serotonin syndrome and can lead to respiratory failure. ${ }^{6}$ These symptoms can be linked to global or limb hypertonia as seen in those intoxications, as described by Mazor et al. ${ }^{4}$

Seizures seem to occur in the first hours following tramadol ingestion and are often isolated. They mostly presented short generalized tonic-clonic seizures, with serotoninergic syndromes or with symptoms of opioid overdose. $^{8-10}$

Antidote naloxone was given in 7 children. Dose of naloxone in infants and children $<5$ years or $<20 \mathrm{~kg} ; 0.1$ $\mathrm{mg} / \mathrm{kg}$ dose; if needed can be repeated every 2 to 3 minutes. In our study no adverse reaction was noted with naloxone. Central nervous system depression and hypoventilation can be treated with naloxone which accelerates recovery, if used early. ${ }^{9}$ Most children recovered spontaneously within the first 24 hours without an antidote treatment. In a multicentre study, Spiller et al reported that the use of naloxone as an antidote was immediately beneficial for apneas and drowsiness in 4 out of 8 patients, in this study in one patient a case of seizure also reported, immediately after administering naloxone, although the seizure could be the residual effect of Tramadol. ${ }^{14}$ In Saidi et al, 43 out of 47 patients over 16 years of age had clinical cerebral state monitor benefits after a naloxone injection. ${ }^{15}$ Side effects were minor in this study.

Two cases died before they reached the hospital. Unfortunately, tramadol intoxication can be fatal if handled too late, this may be due to delay in recognizing symptoms by parents; aspiration during prehospital management; Potential cardiogenic failure with a high plasma level. $^{9}$

In an infant who presented with acute encephalopathy without fever or no known metabolic diseases, the toxicology analysis is crucial to diagnose poisoning. The use of naloxone could be useful as a diagnosis and/or a treatment for tramadol intoxication but should be used carefully due to the lack of available data for the paediatric population.

\section{CONCLUSION}

Because of the increasing use of tramadol practitioners should be aware of its side effects and lethal potential. The handling of the tramadol tablets should be explained to parents and general population and healthcare providers 
in order not to exceed the prescribed dose. Emergency physicians must be aware that when faced with acute neurological deficiency in an infant without fever, drug poisoning is possible and a toxicological analysis is recommended. Naloxone can be efficient when with opioid signs are predominant. Paediatric fatal tramadol poisonings are rare, but causes death if handled too late or cardiac toxicity occurred.

Funding: No funding sources

Conflict of interest: None declared

Ethical approval: The study was approved by the Institutional Ethics Committee

\section{REFERENCES}

1. Beakley BD, Kaye AM, Kaye AD. Tramadol, Pharmacology, Side Effects, and Serotonin Syndrome: A Review. Pain Physician. 2015;18:395-400.

2. Grond S, Sablotzki A. Clinical pharmacology of tramadol. Clin Pharmacokinet. 2004;43:879-923.

3. Orliaguet G, Hamza J, Couloigner V, Denoyelle F, Loriot MA, Broly F, et al. A case of respiratory depression in a child with ultrarapid CYP2D6 metabolism after tramadol. Pediatrics. 2015;135:7535.

4. Mazor SS, Feldman KW, Sugar NF, Sotero M. Pediatric tramadol ingestion resulting in seizure like activity: a case series. Pediatr Emerg Care. 2008;24:380-1.

5. Maréchal C, Honorat R, Claudet I. Serotonin syndrome induced by tramadol intoxication in an 8month-old infant. Pediatr Neurol. 2011;44:72-4.

6. Kahn LH, Alderfer RJ, Graham DJ. Seizures reported with tramadol. JAMA. 1997;278:1661.

7. Sarkar S, Nebhinani N, Singh SM, Mattoo SK, Basu D. Tramadol dependence: a case series from India. Indian J Psychol Med. 2012;34(3):283-5.
8. Márquez-Romero JM, Zermeño-Pohls F, SotoCabrera E. Convulsive status epilepticus associated with a tramadol overdose. Neurologia. 2012;25:583-5.

9. Perdreau E, Iriart X, Mouton JB, Jalal Z, Thambo JB. Cardiogenic shock due to acute tramadol intoxication. Cardiovasc Toxicol. 2015;15:100-3.

10. Grosek S, Mozina M, Grabnar I, Primozic J. Diagnostic and therapeutic value of naloxone after intoxication with tramadol in a young girl. Pediatr Int. 2009;51:842-3.

11. Hassanian-Moghaddam H, Farnaghi F, Rahimi M. Tramadol overdose and apnea in hospitalized children, a review of 20 cases. Res Pharm Sci. 2015;10:544-52.

12. Saudan S, Habre W. Pharmacokinetics of tramadol in children. Ann Fr Anesth Reanim. 2007;26:560-3.

13. Srinivas NR. Differential Consequences of Tramadol in Overdosing: Dilemma of a Polymorphic Cytochrome P450 2D6-Mediated Substrate. J Pain Palliat Care Pharmacother. 2015;29:272-5.

14. Spiller HA, Gorman SE, Villalobos D, Benson BE, Ruskosky DR, Stancavage MM, et al. Prospective multicenter evaluation of tramadol exposure. J Toxicol Clin Toxicol. 1997;35:361-4.

15. Saidi H, Ghadiri M, Abbasi S, Ahmadi SF. Efficacy and safety of naloxone in the management of postseizure complaints of tramadol intoxicated patients: a self-controlled study. Emerg Med J. 2010;27:928-30.

Cite this article as: Sruthi V, Narendra A. Accidental tramadol ingestion in children admitted in tertiary care centre. Int J Basic Clin Pharmacol 2019;8:2661-4. 